\title{
Educação musical e educação especial na produção científica de dissertações e teses
}

\author{
Luciano Ribeiro Cil (Secretaria do Estado da Educação do Paraná, Curitiba, Paraná, Brasil)
}

luciano_cil@hotmail.com

Taísa Grasiela Gomes Liduenha Gonçalves (Universidade Federal de Minas Gerais, Belo Horizonte, Minas Gerais, Brasil)

taisaliduenha@gmail.com

\begin{abstract}
Resumo: A educação musical para a pessoa com deficiência é complexa na educação brasileira por associar a música a aspectos terapêuticos, secundarizando-a como área do conhecimento. Assim, o objetivo do trabalho é analisar a interface da Educação Musical com a Educação Especial na produção acadêmica brasileira. Para tanto, realizou-se um estudo bibliométrico a partir do Banco de Teses e Dissertações da Coordenação de Aperfeiçoamento de Pessoal de Nível Superior (CAPES) e da Biblioteca Digital Brasileira de Teses e Dissertações (BDTD). Os resultados mostraram que a produção na interface educação musical e educação especial é recente, a partir do ano de 2006, com um número reduzido de 17 pesquisas. Deste total de trabalhos, 16 são dissertações de mestrado e um corresponde a uma tese de doutorado, a maioria (53\%) foi desenvolvida no Programa de Pós-Graduação em Música. Todas as produções são de instituições públicas, prevalecendo a temática sobre projetos de educação musical para alunos da educação especial (53\%). Espera-se que este estudo possa subsidiar o debate sobre a educação musical, como conhecimento artístico, para todos os alunos.
\end{abstract}

Palavras-chave: Educação especial; Educação musical; Bibliometria.

Musical education and special education in the scientific production of dissertations and theses

Abstract: Music education for people with disabilities is complex in brazilian education, because of the association of music with therapeutic aspects, putting in second place as area of knowledge. In this context, the purpose of this study is to analyze the interface of Musical Education with Special Education in the Brazilian academic production. Therefore, a bibliometric study was realized from the theses database of the Coordenação de Aperfeiçoamento de Pessoal de Nível Superior (Capes) and of the Digital Library of Thesis and Dissertations (BDTD). The results demonstrated that the production in the area of the interface musical education and special education is recent, since 2006, having a reduced number of 17 researches. From this total, 16 are Masters Dissertations while 01 is a Doctoral Thesis, most of them (53\%) were developed in Music Post Graduate Program. The works are all from public institutions, with emphasis on music education projects for special education students (53\%). It is expected that this study can help subsidize the debate considering musical education, as artistic knowledge, to all students.

Keywords: Special Education; Musical Education; Bibliometrics.

\section{Introdução}

O processo histórico da educação especial mostra a não universalização à educação escolar. Por muitos anos os Estudantes Público-Alvo da Educação Especial (EPAEE) ocuparam espaços em asilos e instituições, sendo privados da convivência social, vivendo à margem da sociedade. De acordo com Aranha (2001), sobretudo a partir da década de 1960, começa-se a discutir sobre esta exclusão, a luta pelo direito das pessoas com deficiência e um movimento de desinstitucionalização começa. Ainda segundo a autora, "[...] pessoas com deficiências físicas e/ou mentais eram ignoradas à sua sorte, buscando a sobrevivência na caridade humana” (ARANHA, 2001, p. 163).

Quando falamos em educação especial, devemos compreender quem faz parte desta modalidade, e quais os serviços oferecidos como suporte para este atendimento. A Lei de Diretrizes e Bases da Educação Nacional - LDBEN (BRASIL, 1996) afirma que a educação especial deve ser oferecida preferencialmente na rede regular de ensino, sendo seu público alunos com deficiência, transtornos globais do desenvolvimento e altas habilidades/superdotação. 
O ensino de música, por sua vez, foi conquistando seu espaço pelas garantias de leis, sendo assegurado na estrutura curricular escolar. A garantia da educação musical como área do conhecimento no componente curricular sofreu e sofre modificações constantes. Desde o período colonial, a música se constituía componente obrigatório do currículo. No decorrer da história, a política educacional passou por mudanças, perdendo-se na polivalência da disciplina de arte (QUEIROZ, 2012).

Atualmente, o Governo Michel Temer encaminhou ao Congresso Nacional a Medida Provisória MP nº 746/2016 (BRASIL, 2016), que dispõe sobre alterações na educação básica, alterando direitos garantidos na Lei $n^{\circ}$ 9.394/96. Desse modo, o ensino de música perde sua obrigatoriedade no percurso de todas as etapas da educação básica.

Diante dessa breve contextualização, a seguir apresentaremos reflexões sobre a interface Educação Musical e Educação Especial.

\section{Educação Musical e Educação Especial}

Historicamente, o Brasil passou por várias discussões sobre a música na estrutura curricular da educação. Tratar da música para a pessoa com deficiência no contexto da educação inclusiva torna ainda mais complexa a discussão. Além da música ser vista como uma atividade para poucos, frequentemente relacionada a "dom", "vocação", "talento", pode surgir, ainda, o desconhecimento de que ela deve ser trabalhada e desenvolvida como outras áreas do conhecimento.

Todo princípio de educação musical é baseado no estudo e propriedade do som. O som é o elemento formador e apresenta propriedades de altura, duração, intensidade e timbre, nas quais o trabalho em educação musical se baseia (LOURO, 2012, p. 21).

As Diretrizes Curriculares para o Ensino de Arte no Paraná para a Educação Básica (PARANÁ, 2008), por exemplo, em seu tópico “música”, nos apresenta estes parâmetros de uma forma bem sucinta e de fácil entendimento, tais como: o timbre é a particularidade de cada som, o que permite distinguir uma voz de uma sirene; duração é a relação do som com o tempo, sons curtos, longos; altura é a relação de um som com o outro, podendo ser mais grave ou mais agudo; intensidade refere-se a qual intensidade o objeto produtor do som é executado, podendo ser mais forte ou mais fraca.

Diante do exposto acima, fica difícil compreender a educação musical por um professor que não seja específico da área, para alunos com ou sem deficiência. Segundo Louro (2012), quando se relaciona música e deficiência, muitos fazem uma associação terapêutica, como se sempre estivéssemos falando da musicoterapia.

O trabalho em educação musical, conforme os Parâmetros Curriculares Nacionais - PCNs de Arte (BRASIL, 1997), não tem relação com musicoterapia. Nas palavras de Louro (2012, p. 23), "precisamos ter em mente que o processo terapêutico é algo bem distinto de um processo pedagógico".

Kebach e Duarte (2012) afirmam que os PCN de Arte (BRASIL, 1997) abordam a música em suas dimensões e objetivos de uma forma muito detalhada, que exalta os benefícios para a formação do humano, entretanto, nem todos os professores utilizam o documento, pois para utilizar os PCN o professor deve dominar a linguagem.

A educação musical para alunos com deficiência, segundo Louro (2006, p. 28), "não distingue o sujeito que se educa, mas os recursos e as formas como os conhecimentos são transmitidos".

Segundo Kebach e Duarte (2012), as artes sempre ficaram minimizadas dentro da educação escolar, não se levando em conta a expressividade que as múltiplas lingua- 
gens podem oferecer, além da linguagem verbal. Durante uma atividade musical pode-se trabalhar a criação da melodia, tocar um instrumento, criar letra ou recitar um poema, expressá-la gestualmente e ritmicamente, envolvendo todos no processo, conforme suas capacidades.

Contudo, notamos que ainda existe uma barreira dos professores do ensino regular em receber EPAEE, ainda mais se falar em trabalhar música com eles. Isto leva a verificar o que já acontece: EPAEE ficando à margem de atividades, inclusive a música, focando apenas em seu caráter lúdico, não como uma forma de linguagem e expressão. A educação musical que seria uma fonte de desenvolver a criatividade e a expressão fica reduzida a reprodução de atividades não criativas, ou ainda, como pano de fundo (KEBACH; DUARTE, 2012, p. 103).

A Educação Musical e a Educação Especial parecem ter em comum o despreparo. Despreparo dos professores que atuam na educação musical, pois a Lei no 11.769/08 garante o ensino da música dentro das Artes, mas não garante o professor licenciado na área (BRASIL, 2008). Na Educação Especial, apesar dos cursos de Pedagogia atualmente apresentarem a disciplina de Educação Especial, não oferecem uma formação de qualidade aos professores (KEBACH; DUARTE, 2012).

Soares (2006) reflete sobre a necessidade de formação de professores de música para atuar nas escolas regulares e também destaca que, nas licenciaturas em música, há poucos conteúdos voltados à formação de um professor para atuar na perspectiva de uma educação inclusiva.

[...] um professor de música que tenha em sua formação elementos da pedagogia, psicologia e uma sólida preparação musical é capaz de analisar as capacidades de seus alunos e planejar atividades musicais que possam contribuir para o desenvolvimento geral da criança, seja ela especial ou não (JOLY, 2003, p. 179).

Consideramos que a pesquisa em questão se justifica por promover uma observância no cenário de trabalhos produzidos dentro desta temática proposta, com o objetivo de analisar a interface da Educação Musical com a Educação Especial na produção acadêmica brasileira.

\section{Procedimentos metodológicos}

Para o desenvolvimento da pesquisa, optamos pelo estudo bibliométrico, uma metodologia que nos permite, segundo Hayashi et al. (2007, p. 4), "analisar a atividade científica ou técnica pelo estudo quantitativo das publicações e o seu principal objetivo é o desenvolvimento de indicadores cada vez mais confiáveis”.

Segundo Hayashi et al. (2007), o estudo bibliométrico se difundiu no Brasil na década de 1970, incentivado pelo Instituto Brasileiro de Bibliografia e Documentação (IBBD), atual Instituto Brasileiro de Informação em Ciência e Tecnologia (IBICT). Araújo (2007) destaca que, apesar da diminuição deste enfoque de pesquisa na década de 1980, com o advento das novas tecnologias, especialmente o uso do computador, na década seguinte (1990), houve um grande interesse, novamente, pela utilização das metodologias quantitativas, e a bibliometria retoma o crescimento, como ferramenta, no campo das pesquisas.

O avanço das tecnologias, segundo Hayashi et al. (2007), mudou nossa maneira de pesquisar. As teses e dissertações das universidades, assim que defendidas, são disponibilizadas em bibliotecas digitais, dando um acesso ampliado ao que antes era de difícil acesso, bem como a consulta de periódicos, livros completos e diversas pla- 
taformas que nos permitem uma gama confiável de materiais produzidos pela comunidade científica. "A análise bibliométrica é um método flexível para avaliar a tipologia, a quantidade e qualidade das fontes de informação citadas em pesquisas. O produto da análise bibliométrica são os indicadores científicos desta produção" (SILVA; HAYASHI; HAYASHI, 2011, p. 113-114).

Cabe reiterar que nosso campo de pesquisa restringiu-se ao Banco de Teses e Dissertações da Coordenação de Aperfeiçoamento de Pessoal de Nível Superior (CAPES) e a Biblioteca Digital Brasileira de Teses e Dissertações (BDTD). Deste modo, foi definido como critério de inclusão todas as teses, dissertações e artigos a serem analisados, independente de um período temporal pré-estabelecido, ou seja, foi coletado o total de registros disponíveis nas bases de dados (CAPES e BDTD).

O Banco de Teses e Dissertações da CAPES disponibiliza ferramentas de busca, as quais nos permitiram acessar teses e dissertações defendidas nos programas de pós-graduação brasileiro desde 1987. O banco oferece credibilidade, pois as informações contidas são disponibilizadas pelos próprios programas das universidades, que são responsáveis pela veracidade do conteúdo dos materiais encaminhados.

Da mesma forma, a utilização da BDTD, a qual foi concebida pelo Instituto Brasileiro de Informação em Ciência e Tecnologia (IBICT), confere esta confiabilidade e veracidade dos dados fornecidos, se destacando, há mais de dez anos, como uma das maiores e mais completas ferramentas de consulta das produções de teses e dissertações de autores brasileiros.

A intenção de utilizarmos estas duas plataformas - CAPES e BDTD - foi de garantir o acesso ao maior número de teses e dissertações produzidas na temática proposta.

Para a coleta de dados recorremos a uma planilha de Excel de acordo com as orientações de Hayashi (2013) e Silva, Hayashi e Hayashi (2011), que consiste em uma tabulação em planilha Excel.

A planilha contempla campos específicos como: termo de busca, gênero do autor, autor, título, orientador, gênero do orientador, ano da defesa, nível (mestrado/ doutorado), Instituição de Ensino Superior, região do país, dependência administrativa, programa de pós-graduação, área de conhecimento, linha de pesquisa, agência financiadora, palavras-chave e resumo.

Assim, para consulta nos bancos de dados e tabulação, definimos os seguintes termos descritores: "ensino de música inclusão", "ensino de música deficiência”, "ensino de música educação especial”, "educação musical deficiência”, "educação musical inclusão", "música deficiência”, "música inclusão”, "música educação especial”, "educação musical educação especial” e "educação musical especial”.

Os termos (palavras-chave) foram aplicados às plataformas da CAPES e da BDTD sem restrição de datas em que as teses e/ou dissertações foram produzidas, com consultas entre os dias 10 e 20 de outubro de 2016. Os descritores foram aplicados entre aspas com o intuito de contemplar a expressão indicada na íntegra, isto é, a tese e/ou dissertação deveria contemplar todas as palavras-chave da expressão, sempre estabelecendo uma interface da música com a educação especial.

\section{Resultados e Discussão}

Para darmos início ao tratamento dos dados coletados, foi necessário chegar a um número exato de dissertações e teses produzidas na interface educação musical e 
educação especial. Como trabalhamos com a bibliometria, estes dados foram coletados seguindo um mesmo padrão de busca nos bancos de dados, de modo a garantir veracidade à pesquisa.

Encontramos um total de 16 dissertações de mestrado e 1 tese de doutorado, no período 2006-2015, a partir das palavras-chave selecionadas. Vale ressaltar que este número de produções encontradas se refere exclusivamente ao período (data) em que os dados elencados na planilha foram coletados, podendo haver variações se aplicado em outros períodos, em virtude da constante realimentação dos bancos da CAPES e da BDTD/IBICT.

Cabe salientarmos que os 17 trabalhos de dissertações e teses foram defendidos, na sua totalidade, em universidades públicas, não havendo registros do tema abordado em Instituição de Ensino Superior (IES) do setor privado, conforme demonstra o quadro a seguir.

\begin{tabular}{|c|c|}
\hline IES & TOTAL DE TRABALHOS \\
\hline UNICAMP & $\mathbf{0 2}$ \\
\hline UFRJ & $\mathbf{0 1}$ \\
\hline UNESP & $\mathbf{0 1}$ \\
\hline UFPA & $\mathbf{0 1}$ \\
\hline UFPB & $\mathbf{0 1}$ \\
\hline UFG & $\mathbf{0 1}$ \\
\hline UFBA & $\mathbf{0 2}$ \\
\hline UFSCAR & $\mathbf{0 3}$ \\
\hline UFSM & $\mathbf{0 2}$ \\
\hline UNIRIO & $\mathbf{0 1}$ \\
\hline UFMG & $\mathbf{0 1}$ \\
\hline UDESC & $\mathbf{0 1}$ \\
\hline TOTAL & $\mathbf{1 7}$ \\
\hline
\end{tabular}

Quadro 1 - Distribuição de trabalhos por IES no período de 2006 a 2015

Fonte: Banco de Teses e Dissertações da CAPES, BDTD/IBICT - Elaboração dos autores.

Conforme o Quadro 1, podemos notar que a região Sudeste do país apresenta a maior produção de trabalhos na área, com um total de 8 estudos, seguida da região Nordeste e Sul com 3 trabalhos cada e as regiões Norte e Centro-Oeste, com uma publicação cada.

A seguir apresentaremos os Programas de Pós-Graduação (PPG) que desenvolveram pesquisas nas áreas de Multimeios, Artes, Educação Especial, Educação e Música. 


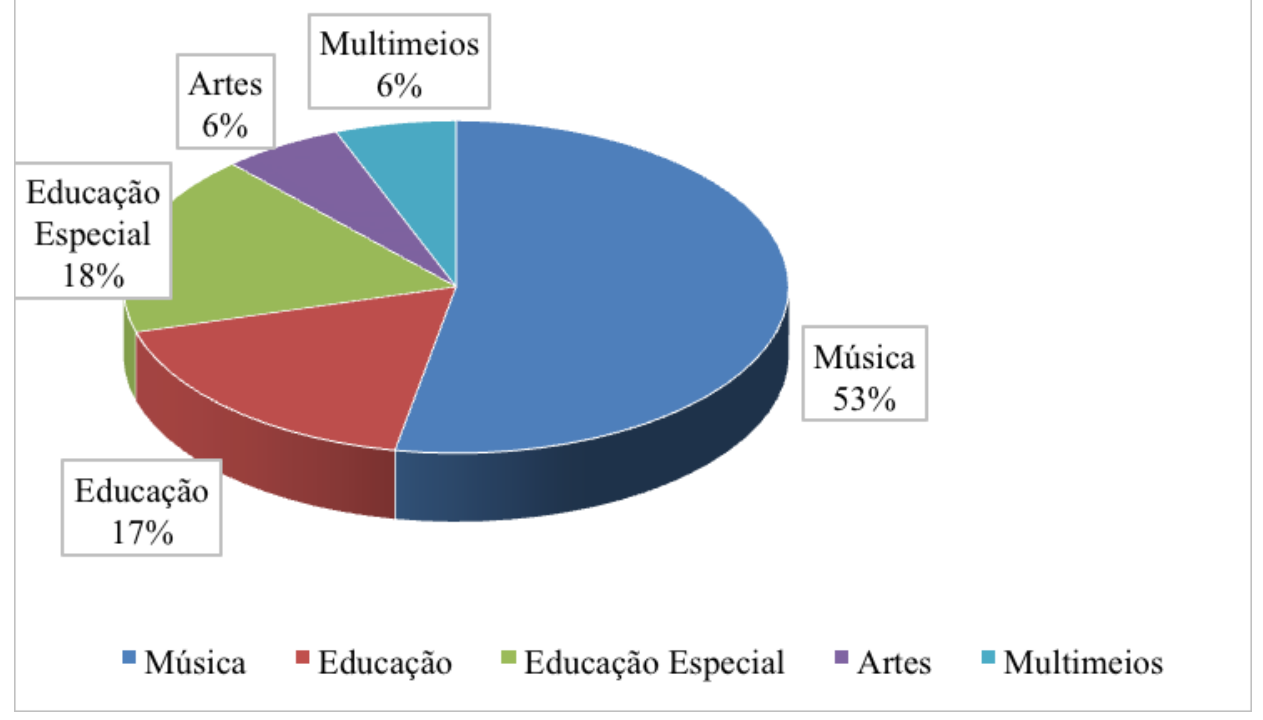

Gráfico 1 - Áreas dos Programas de Pós-Graduação nas teses e dissertações no período de 2006 a 2015 Fonte: Banco de Teses e Dissertações da CAPES, BDTD/IBICT - Elaboração dos autores.

Podemos identificar, pelo Gráfico 1, os PPG que desenvolveram pesquisas dentro da temática. Os PPG em Música somam 9 dos 17 trabalhos produzidos, perfazendo 53\% do total, seguido dos Programas de Educação Especial (18\%), Educação (17\%), Artes (6\%) e Multimeios (6\%).

Para a descrição e análise das dissertações e teses, elaboramos o Quadro 2, que mostra, em ordem cronológica, os trabalhos (mestrado e/ou doutorado), com descrição de seus devidos autores, orientadores e títulos.

\begin{tabular}{|l|l|l|l|}
\hline $\begin{array}{c}\text { Ano da Defesa } \\
\text { Mestrado/ } \\
\text { Doutorado }\end{array}$ & \multicolumn{1}{|c|}{ Autor } & \multicolumn{1}{|c|}{ Orientador } & \multicolumn{1}{c|}{ Título } \\
\hline 2006 - Mestrado & $\begin{array}{l}\text { Cybelle Maria } \\
\text { Veiga Loureiro }\end{array}$ & $\begin{array}{l}\text { Maria Cecília } \\
\text { Cavalieri França }\end{array}$ & $\begin{array}{l}\text { Musicoterapia na educação musical } \\
\text { especial de portadores de atraso do } \\
\text { desenvolvimento leve e moderado na } \\
\text { rede regular de ensino }\end{array}$ \\
\hline 2006 - Mestrado & Lisbeth Soares & $\begin{array}{l}\text { Ana Lúcia } \\
\text { Cortegoso }\end{array}$ & $\begin{array}{l}\text { Formação e prática docente musical } \\
\text { no processo de educação inclusiva de } \\
\text { pessoas com necessidades especiais }\end{array}$ \\
\hline 2007 - Mestrado & $\begin{array}{l}\text { Rusiel Paulino } \\
\text { de Araújo Júnior }\end{array}$ & $\begin{array}{l}\text { Janine Marta } \\
\text { Coelho Rodrigues }\end{array}$ & $\begin{array}{l}\text { A educação musical inclusiva } \\
\text { nas escolas de educação básica: } \\
\text { perspectivas conceituais e metodológicas }\end{array}$ \\
\hline 2008 - Mestrado & $\begin{array}{l}\text { Claudia Eboli } \\
\text { Corrêa dos } \\
\text { Santos }\end{array}$ & $\begin{array}{l}\text { José Nunes } \\
\text { Fernandes }\end{array}$ & $\begin{array}{l}\text { A educação musical especial: aspectos } \\
\text { históricos, legais e metodológicos }\end{array}$ \\
\hline 2010 - Mestrado & $\begin{array}{l}\text { Catarina Shin } \\
\text { Lima de Souza }\end{array}$ & $\begin{array}{l}\text { Luiz Cesar } \\
\text { Marques } \\
\text { Magalhães }\end{array}$ & $\begin{array}{l}\text { Música e inclusão: necessidades } \\
\text { educacionais especiais ou necessidades } \\
\text { profissionais especiais? }\end{array}$ \\
\hline 2010 - Mestrado & $\begin{array}{l}\text { Daniela dos } \\
\text { Santos Morales }\end{array}$ & $\begin{array}{l}\text { Cláudia Ribeiro } \\
\text { Bellochio }\end{array}$ & $\begin{array}{l}\text { Música na docência de educadoras } \\
\text { especiais: um estudo nas escolas de } \\
\text { Santa Maria/RS }\end{array}$ \\
\hline
\end{tabular}




\begin{tabular}{|c|c|c|c|}
\hline 2010 - Doutorado & $\begin{array}{l}\text { Fabiana Fator } \\
\text { Gouvêa Bonilha }\end{array}$ & \begin{tabular}{|l|} 
Claudiney \\
Rodrigues \\
Carrasco \\
\end{tabular} & $\begin{array}{l}\text { Do toque ao som: O ensino da } \\
\text { musicografia Braile como um caminho } \\
\text { para a educação inclusiva }\end{array}$ \\
\hline 2010 - Mestrado & $\begin{array}{l}\text { Viviane Cristina } \\
\text { Drogomirecki }\end{array}$ & Eliane Leão & $\begin{array}{l}\text { Educação Musical Inclusiva - Um estudo } \\
\text { dos dados do projeto Arte Inclusão do } \\
\text { Centro Profissional em Artes Basileu } \\
\text { França (CEPABF) }\end{array}$ \\
\hline 2013 - Mestrado & $\begin{array}{l}\text { José Carlos } \\
\text { Quintanilha }\end{array}$ & $\begin{array}{l}\text { Thelma Beatriz } \\
\text { Sydenstricker } \\
\text { Alvares }\end{array}$ & $\begin{array}{l}\text { Uma oficina de música para alunos } \\
\text { com deficiências visuais: Construção de } \\
\text { instrumentos musicais com materiais } \\
\text { alternativos }\end{array}$ \\
\hline 2013 - Mestrado & $\begin{array}{l}\text { Juliane Riboli } \\
\text { Correa }\end{array}$ & $\begin{array}{l}\text { Claudia Ribeiro } \\
\text { Bellochio }\end{array}$ & $\begin{array}{l}\text { Construindo conhecimentos musicais } \\
\text { e pedagógico-musicais em grupo: } \\
\text { experiências formativas na educação } \\
\text { especial }\end{array}$ \\
\hline 2013 - Mestrado & $\begin{array}{l}\text { Katia Daniela } \\
\text { Cucchi }\end{array}$ & $\begin{array}{l}\text { Ricardo Mazzini } \\
\text { Bordini }\end{array}$ & $\begin{array}{l}\text { Software Musibraille: a interface entre } \\
\text { educador leigo em musicografia braille e } \\
\text { educando cego }\end{array}$ \\
\hline 2013 - Mestrado & $\begin{array}{l}\text { Tassila } \\
\text { Crystiane Freitas } \\
\text { Albuquerque }\end{array}$ & $\begin{array}{l}\text { Aureo Deo de } \\
\text { Freitas Junior }\end{array}$ & $\begin{array}{l}\text { Educação Musical e Inclusão: } a \\
\text { experiência do Programa Cordas da } \\
\text { Amazônia }\end{array}$ \\
\hline 2014 - Mestrado & $\begin{array}{l}\text { Shirlei Escobar } \\
\text { Tudissaki }\end{array}$ & $\begin{array}{l}\text { Sonia Regina } \\
\text { Albano de Lima } \\
\end{array}$ & $\begin{array}{l}\text { Ensino de música para pessoas com } \\
\text { deficiência visual }\end{array}$ \\
\hline 2014 - Mestrado & $\begin{array}{l}\text { Valeria Peres } \\
\text { Asnis }\end{array}$ & $\begin{array}{l}\text { Ana Lucia } \\
\text { Cortegoso }\end{array}$ & $\begin{array}{l}\text { Relações entre habilidades musicais } \\
\text { e habilidades sociais em pessoas com } \\
\text { Síndrome de Williams: perspectivas e } \\
\text { limitações }\end{array}$ \\
\hline 2014 - Mestrado & $\begin{array}{l}\text { Vivian } \\
\text { Leichsenring } \\
\text { Kuntze }\end{array}$ & $\begin{array}{l}\text { Regina Finck } \\
\text { Schambeck }\end{array}$ & $\begin{array}{l}\text { A relação do surdo com a música: } \\
\text { representações sociais }\end{array}$ \\
\hline 2015 - Mestrado & $\begin{array}{l}\text { Ana Celia de } \\
\text { Lima Viana }\end{array}$ & \begin{tabular}{|l} 
Tania Maria \\
Santana de Rose
\end{tabular} & $\begin{array}{l}\text { Uma proposta de capacitação na área } \\
\text { da educação musical especial }\end{array}$ \\
\hline 2015 - Mestrado & $\begin{array}{l}\text { Pamela de } \\
\text { Bortoli Machado }\end{array}$ & $\begin{array}{l}\text { Fabio Nauras } \\
\text { Akhras }\end{array}$ & $\begin{array}{l}\text { A representação de inclusão social } \\
\text { e digital por meio da música em } \\
\text { documentários brasileiros }\end{array}$ \\
\hline
\end{tabular}

Quadro 2 - Teses e dissertações na interface Educação Musical e Educação Especial Fonte: Banco de Teses e Dissertações da CAPES, BDTD/IBICT - Elaboração dos autores.

Estes resultados mostram que o tema em questão vem sendo recentemente trabalhado, pois os trabalhos foram produzidos dentro de um período de nove anos. Nos anos de 2009, 2011 e 2012, não houve nenhuma produção, contudo, um leve crescimento da pesquisa na área aparece a partir de 2013.

A partir desse levantamento, analisaremos a relação estabelecida pelos autores entre as áreas da educação especial e educação musical em suas dissertações e teses, apresentando título, objetivos, metodologia e considerações finais de cada trabalho.

Loureiro (2006), em sua dissertação Musicoterapia na educação musical especial de portadores de atraso do desenvolvimento leve e moderado na rede regular de ensino, salienta que a musicoterapia no sistema educacional inclusivo na pré-escola e no ensino fundamental favorece o desenvolvimento de habilidades perceptuais, motoras, cognitivas e sociais. A autora propõe, por meio de uma revisão bibliográfica, estratégias e 
adaptações metodológicas para a prática da educação musical destes alunos no ensino regular baseando-se em teorias de Piaget e Vygotsky. Nas conclusões, apresenta a necessidade da formação docente, com conhecimento tanto em música quanto em educação especial, impulsionando o desenvolvimento da interação sociocultural do aluno. A autora ressalta a importância do profissional especializado em educação musical nas escolas brasileiras.

O estudo apresentado por Soares (2006) - Formação e prática docente musical no processo de educação inclusiva de pessoas com necessidades especiais - faz uma análise das práticas e formações dos professores que atendem EPAEE no ensino regular e que trabalham com a educação musical. A pesquisa foi desenvolvida com três professores que trabalham na rede particular de ensino da educação básica em uma cidade da grande São Paulo. A coleta de dados procedeu-se por meio de análise das concepções de educação musical, educação especial e inclusão pelos professores envolvidos de forma a descrever a atuação do professor de música em relação ao público-alvo da educação especial no contexto da educação musical. Os resultados indicaram que os três professores participantes não apresentavam formação específica em música, seja licenciatura ou bacharelado, eles apresentavam cursos técnicos na área, por isso atuavam com educação musical. Também não apresentavam formação específica (especialização ou cursos de formação) para atuar com EPAEE. Assim, por não terem uma formação específica para a atuação, os planejamentos partiam de modo aleatório, não considerando uma proposta curricular ou uma diretriz específica para a educação musical. As atividades propostas verificadas na pesquisa não contemplavam a inclusão de todos nas atividades, em virtude do desconhecimento e da ausência de formação dos professores atuantes.

A dissertação $A$ educação musical inclusiva nas escolas de educação básica: perspectivas conceituais e metodológicas, de Araújo Júnior (2007), investigou duas escolas municipais de João Pessoa (PB) que apresentam maior número de alunos com necessidades educacionais especiais (NEE) incluídos. O objetivo da pesquisa foi refletir sobre o processo de inclusão e a contribuição da música para as aprendizagens sociais e escolares. Os procedimentos metodológicos foram observações sistemáticas, registros e questionários respondidos por professores e gestores. A pesquisa revelou a escassa bibliografia da área da Educação Musical Especial e a exclusão da música no ambiente escolar; professores com formação em licenciatura em música apresentando falta de conhecimento sobre a educação especial; ausência da música na disciplina de Artes; e falta de metodologias que promovam o ensino de música para o público da educação especial. Nas conclusões, o autor discorre sobre a necessidade de reformulações curriculares. Destaca que a educação musical, proposta nas diretrizes, não aconteceu nas escolas analisadas e que os educadores musicais não fazem uma interface com outras áreas do conhecimento.

A dissertação de Santos (2008), intitulada A educação musical especial: aspectos históricos, legais e metodológicos, objetivou investigar concepções acerca da Educação Musical Especial em escolas do município do Rio de Janeiro. Para tanto, os professores atuantes em música nestas escolas responderam a questionários. Os resultados da pesquisa mostraram que a maioria dos professores tem formação complementar em Musicoterapia para atuação na educação especial; sua efetivação como área do conhecimento dentro das artes é deixada de lado; quando associada, então, à educação especial, verifica, ainda, uma maior ausência. $\mathrm{O}$ autor constatou que a educação musical acontecia na minoria das escolas que fizeram parte do seu campo de pesquisa e de forma deficitária. Diante desse contexto, a educação musical acaba buscando outros espaços não escolares. 
Na dissertação Música e inclusão: necessidades educacionais especiais ou necessidades profissionais especiais?, Souza (2010) analisou o papel do educador musical nas constantes mudanças ocorridas na legislação nacional, relacionando com a área da educação especial. Deste modo, utilizou-se de questionários para verificar as dificuldades dos educadores musicais diante do público da educação especial. A pesquisa mostrou que não bastam apenas leis que garantam uma educação inclusiva, sendo necessária formação dos professores e propostas de atuação na área da educação especial, rompendo com estereótipos e preconceitos. A autora traz à tona o questionamento da preparação específica em educação especial para atuar em educação musical.

A pesquisa de Morales (2010), Música na docência de educadoras especiais: um estudo nas escolas de Santa Maria/RS, teve como objetivo verificar, por meio de entrevistas, como 15 educadoras trabalham a música em suas aulas. Os resultados revelaram que todas as professoras participantes possuíam formação em educação especial seja na graduação seja na especialização, mas nenhuma apresentava formação técnica ou superior em música, apenas vivência em música. Outro dado identificado foi que muitas professoras utilizavam a música como pano de fundo para o desenvolvimento de outras atividades. A autora constatou que a música é vista mais como recurso terapêutico do que área de conhecimento, aproximando mais de aspectos da musicoterapia do que da educação musical.

A tese de Bonilha (2010), sob o título Do toque ao som: O ensino da musicografia Braile como um caminho para a educação inclusiva, apresentou como objetivo verificar as dificuldades dos indivíduos envolvidos diante da alfabetização musical em braile. Para tanto, realizou uma pesquisa com três pessoas que passam pelo processo de aprendizado da notação musical para cegos. O trabalho resultou em obras de áudio-documentários como também na criação de um acervo de obras transcritas para a Musicografia Braile.

O estudo de Drogomirecki (2010), intitulado Educação Musical Inclusiva - um estudo dos dados do projeto Arte Inclusão do Centro Profissional em Artes Basileu França (CEPABF), teve como objetivo verificar as aprendizagens de educandos da educação especial no ensino de Arte/Música pautando-se nos dados documentais resultantes do Projeto Arte Inclusão. Os resultados da pesquisa mostraram que o projeto acontecia no contraturno, não fazendo parte da grade de Arte no período regular, o que favoreceu o processo de ensino e aprendizagem dos alunos da educação especial.

A dissertação de Quintanilha (2013), intitulada Uma oficina de música para alunos com deficiências visuais: construção de instrumentos musicais com materiais alternativos, propõe procedimentos didáticos para o ensino de música aos alunos com deficiência visual em uma instituição especial. Os resultados foram os instrumentos musicais produzidos e adaptados pelos alunos com deficiência visual valorizando suas potencialidades no processo pedagógico.

Em sua pesquisa, Correa (2013) investigou de que forma um grupo de alunas da Educação Especial em formação da Universidade Federal de Santa Maria no RS, apresenta experiências musicais e pedagógico-musicais. Os resultados apontados foram: o desempenho do grupo mediando experiências formativas musicais e pedagógico-musicais na Educação Especial e a música como um conhecimento que potencializa desenvolvimento.

Cucchi (2013) traz uma especificidade em sua pesquisa Software musibraille: $a$ interface entre educador leigo em musicografia Braile e educando cego, com o objetivo de verificar a utilização do software na aplicação da teoria musical, identificando as difi- 
culdades do aluno cego em sua utilização e as competências do educador no processo de ensino de música ao aluno deficiente visual. Os resultados mostraram que o educando manuseou o software em nível básico, porém necessita de mais estudos para melhorar a sua performance em relação ao seu manuseio. No que se refere ao educador, o estudo verificou ausência de preparo em nível profissional e falta de recursos apropriados para a prática pedagógica.

O estudo de Albuquerque (2013), intitulado Educação Musical e Inclusão: a experiência do Programa Cordas da Amazônia, teve como objetivo descrever a inclusão de alunos com transtorno do desenvolvimento e dificuldades de aprendizagem no projeto "Cordas da Amazônia” da Universidade Federal do Pará, sob o olhar da educação musical inclusiva. Deste modo, foram utilizadas entrevistas com um técnico, um aluno e com o coordenador do projeto. Os resultados indicaram que o professor, ao ingressar no programa, conhece as principais características comportamentais do aluno que passou por avaliação com a equipe técnica. Neste contexto, desenvolve atividades que favoreçam a aquisição de comportamentos pelos alunos. Ao término da intervenção, o aluno pode continuar os estudos de música, caso interesse.

Tudissaki (2014) desenvolveu uma pesquisa bibliográfica em teses e dissertações que abordavam o tema Ensino de música para pessoas com deficiência visual. A autora constatou que os cursos de Licenciatura em Música/Educação Musical das universidades públicas do Estado de São Paulo não oferecem disciplinas voltadas ao ensino de música para pessoas com deficiência visual, desse modo, o autor contemplou ferramentas e materiais de apoio pedagógico para trabalhar música com o deficiente visual.

Asnis (2014) pesquisou sobre um programa de educação musical para adolescentes com Síndrome de Willians e pautou-se na intervenção com duração de 13 semanas para um dos participantes e nove semanas para o outro participante, com uma aula semanal de aproximadamente 30 minutos cada. Chegou a conclusão de que o programa foi relevante para o aprendizado de educação musical.

O trabalho de Kuntze (2014), intitulado A relação do surdo com a música: representações sociais, teve como objetivo compreender as dificuldades que o deficiente auditivo tem em se apropriar da música. Para tanto, foram observados dois grupos de alunos surdos, sendo um grupo musicalizado e o outro não. Os resultados mostraram que as vivências musicais do surdo são importantes para seu posicionamento como sujeito musical, interferindo diretamente nas representações sociais. Além disso, constatou-se a necessidade de profissionais especializados que atuem na interface entre música e surdez, com metodologias e práticas pedagógicas que possibilitem o ensino musical à comunidade surda.

Viana (2015), em sua dissertação Uma proposta de capacitação na área da educação musical especial, aborda a questão da música para alunos com NEE diante da promulgação da Lei $n^{0}$ 11.769/08. Para tanto, produziu um curso de nove encontros com três educadores musicais para trabalharem a música, desenvolvendo estratégias e metodologias para atuarem com EPAEE. A autora destaca a escassez de materiais produzidos relacionando a educação musical com a educação especial.

Por sua vez, a dissertação de Machado (2015) analisou A representação de inclusão social e digital por meio da música em documentários brasileiros. A dissertação desenvolveu-se com base na análise dos conceitos de inclusão social, inclusão digital, identidade cultural e revolução digital no mercado musical baseando-se em documentários.

Após a verificação das dissertações e teses, e extraída sua síntese de enfoque do 
trabalho de pesquisa, pudemos destacar as temáticas relacionadas à interface educação especial e educação musical, explicitadas no Gráfico 2.
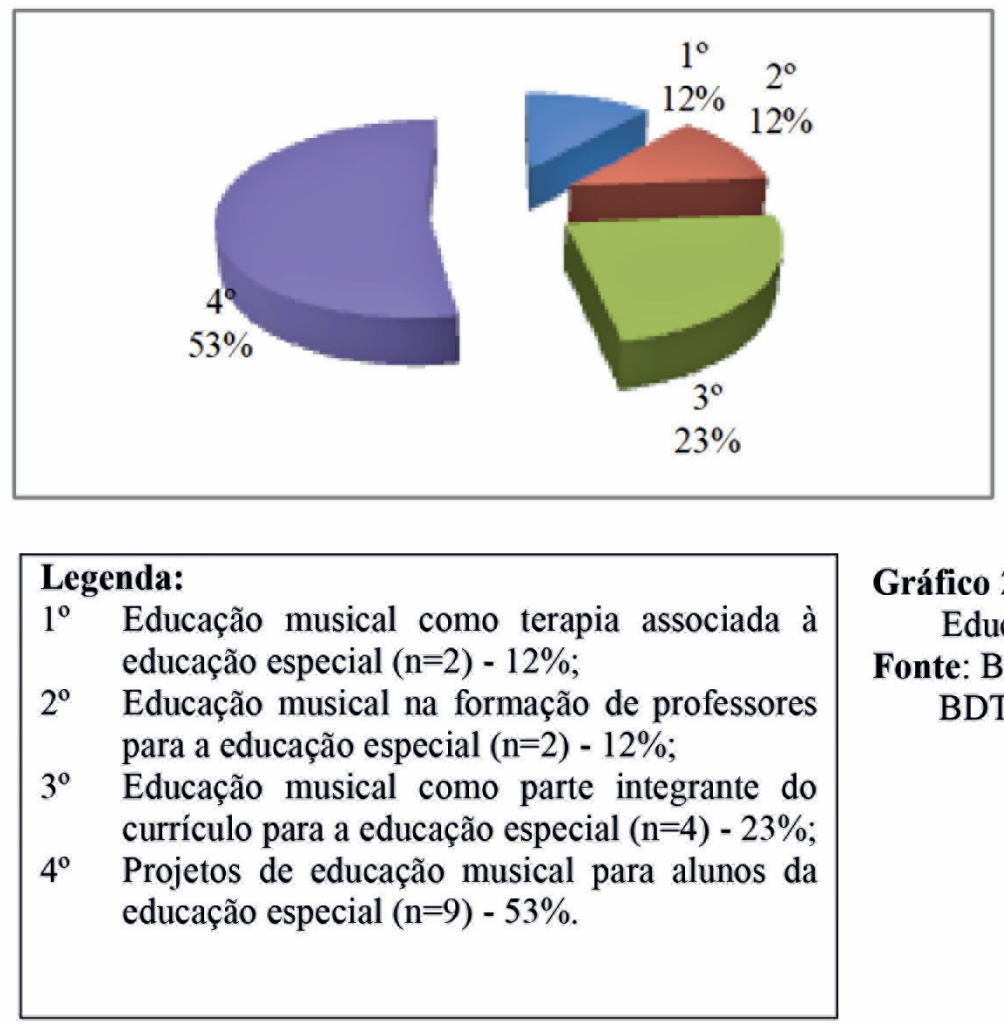

Gráfico 2 - A interface entre Educação Musical e Educação Especial segundo as temáticas

Fonte: Banco de Teses e Dissertações da CAPES, BDTD/IBICT - Elaboração dos autores,.

A educação musical, direcionada ou não para o público-alvo da educação especial, deve ser contemplada no contexto da educação escolar, contribuindo na formação integral do ser humano.

[...] a música é um tipo de arte com imenso potencial educativo já que, a par de manifestação estética por excelência, explicitamente ela se vincula a conhecimentos científicos ligados à física e à matemática além de exigir habilidade motora e destreza manual que a colocam, sem dúvida, como um dos recursos mais eficazes na direção de uma educação voltada para o objetivo de se atingir o desenvolvimento integral do ser humano. (SAVIANI, 2000, p. 42).

Deste modo, o ensino de música ao público-alvo da educação especial, na escola regular, não deve se restringir ao modo terapêutico.

Percebemos, no decorrer da pesquisa, a dificuldade em encontrar a educação musical de uma forma estruturada na escola. Loureiro (2006) descreve a música presente nas escolas em momentos de lazer, como horários de recreio, em festividades do calendário escolar, mas sua ausência como disciplina sistemática no cenário escolar brasileiro ainda é registrada. Professores utilizam a música para alfabetização, música para concentração, música como pano de fundo. Loureiro (2006, p. 21) alerta que "é fundamental uma análise para redimensionar o papel da música na escola e buscar condições necessárias para que ela possa vir a ter valor significativo no processo de educação escolar".

Nesse contexto, Soares (2006) enfatiza a necessidade da formação do professor para atuar na educação musical e na área da educação especial, e acrescenta que os cursos superiores em música devem incluir em seus currículos reflexões sobre a inclusão. A autora critica a significação da arte, enfatizando que não deve reduzir-se ao aspecto 
funcional de resultados, como meras apresentações em festividades.

Desde a Lei n ${ }^{0} 5.692 / 71$, a qual contempla a implantação do ensino das artes, evidenciou-se a dificuldade com relação ao professor atuante na área. Diante de sua formação polivalente em educação artística, a música como área do conhecimento parece irrelevante, ganhando características recreativas e festivas (LOUREIRO, 2006, p. 27). Esta observação de Loureiro (2006) ocorre tanto na escola regular quanto nas escolas na modalidade de educação especial, em que o caráter recreativo e festivo foi e ainda é muito marcante.

Ferreira e Duarte (2011) defendem o conteúdo artístico na escola de forma curricular, e não em contrapartida aos outros saberes, com o objetivo do desenvolvimento integral do humano e ressaltam,

[...] o desenvolvimento das artes nunca esteve dissociado do conhecimento objetivo da natureza e da sociedade, assim como o desenvolvimento das ciências nunca ocorreu sem um intenso envolvimento afetivo dos indivíduos para com a atividade investigativa (FERREIRA; DUARTE, 2011, p. 121).

Diante do exposto, cabe destacarmos o número de pesquisas que focam projetos específicos de música, em que profissionais habilitados na área de música trabalham os conteúdos musicais, se distanciando do ambiente escolar. As atividades ocorrem em turnos opostos à educação regular, não contemplados na disciplina de Arte. Almejamos, entretanto, que estes conteúdos e adaptações metodológicas constituam o currículo escolar.

\section{Algumas considerações}

Nesta pesquisa, por meio do estudo bibliométrico, analisamos a interface da Educação Musical com a Educação Especial na produção acadêmica brasileira.

O estudo bibliométrico nos permitiu identificar que as produções científicas na interface educação musical e educação especial é recente, a partir do ano de 2006, com um número reduzido de 17 pesquisas. Deste total de trabalhos, 16 são dissertações de mestrado e apenas uma corresponde a tese de doutorado, a maioria (53\%) foi realizada em Programa de Pós-Graduação em Música. Todas as produções são de instituições públicas.

Ao associar educação musical à educação especial verificamos pontos ainda obscuros de definição tanto do trabalho especializado com EPAEE quanto da especialidade de quem trabalha com o ensino de música.

As análises das pesquisas compiladas mostraram que o trabalho desenvolvido em música para o público-alvo da educação especial é, de certa forma, recente, e ainda escasso. A observação da temática em trabalhos de pesquisa se restringiu aos últimos nove anos.

Como mencionamos no decorrer do texto, o intuito desta pesquisa foi analisar como a educação musical tem sido desenvolvida na educação especial. Observamos trabalhos que discutiram sobre a característica terapêutica da música na educação destes indivíduos. Ressaltamos que o foco deste estudo não é avaliar a música na perspectiva terapêutica, entretanto, de acordo com as diretrizes curriculares, a música se constitui como área de conhecimento no ambiente escolar. Diante disso, o ambiente escolar visa, entre outros aspectos, desenvolver o humano em todas as suas áreas, portanto, a música como área do conhecimento e formação do humano deve ser contemplada. 
Cabe refletirmos, também, sobre a formação dos professores no ensino de música e na educação especial. O professor que não conhece os conteúdos pertinentes à educação musical, pode realizar concepções errôneas no ambiente escolar. Por conseguinte, a área da educação especial também precisa ser conhecida e apropriada pelo professor para que compreenda o percurso histórico de luta pelo direito à educação formal.

Além disso, a educação musical está sendo difundida por meio de projetos de inclusão social. Evidenciando-se, assim, o afastamento do ensino de música da educação escolar como exigência curricular.

Nesse estudo, apesar do rigor metodológico, não tivemos a pretensão de esgotar toda a produção científica das temáticas investigadas. Esperamos que as reflexões apontadas nesse trabalho possam contribuir para o meio científico, sobretudo promovendo discussões e pesquisas sobre o ensino de música para os EPAEE.

\section{Agradecimentos}

Agradecemos ao PROSUP/CAPES pelo suporte financeiro.

\section{Referências}

ALBUQUERQUE, Tassila Crystiane Freitas. Educação Musical e Inclusão: a experiência do Programa Cordas da Amazônia. 2013. 104 f. Dissertação (Mestrado em Artes) - Instituto de Ciências da Arte, Universidade Federal do Pará, Belém, 2013.

ARANHA, Maria Salete Fábio. Paradigmas da relação da sociedade com as pessoas com deficiência. Revista do Ministério Público do Trabalho, Brasília, v. 11, n. 21, p. 160-173, 2001.

ARAÚJO, Carlos Alberto. Bibliometria: evolução histórica e questões atuais. Em Questão, Porto Alegre, v. 12, n. 1, p. 11-32, jan./jun. 2007.

ARAÚJO JÚNIOR, Rusiel Paulino de. A educação musical inclusiva nas escolas de educação básica: perspectivas conceituais e metodológicas. 2007. 145 f. Dissertação (Mestrado em Educação) - Programa de Pós-Graduação em Educação, Universidade Federal da Paraíba, João Pessoa, 2007.

ASNIS, Valeria Peres. Relações entre habilidades musicais e habilidades sociais em pessoas com Síndrome de Williams: perspectivas e limitações. 2014. 117 f. Dissertação (Mestrado em Educação Especial) - Programa de Pós-Graduação em Educação Especial, Universidade Federal de São Carlos, São Carlos, 2014.

BONILHA, Fabiana Fator Gouvêa. Do toque ao som: o ensino da musicografia braile como um caminho para a educação musical inclusiva. 2010. 261 f. Tese (Doutorado em Música) - Pós-Graduação do Departamento de Música, Universidade Estadual de Campinas, Campinas, São Paulo, 2010.

BRASIL. Câmara dos Deputados. Lei no 5.692, de 11 de agosto de 1971. Fixa Diretrizes e Bases para o ensino de $1^{\circ}$ e $2^{\circ}$ graus, e dá outras providências. Diário Oficial da União, Brasília, DF, 12 ago. 1971. Seção 1, p. 6377.

Presidência da República. Casa Civil. Subchefia para Assuntos Jurídicos. Lei no 9.394 , de 20 de dezembro de 1996. Estabelece as diretrizes e bases da educação nacional. Diário Oficial da União, Brasília, DF, 23 dez. 1996.

. Ministério da Educação e do Desporto. Secretaria de Educação Fundamental. Parâmetros Curriculares Nacionais. Brasília, DF: MEC/ SEF, 1997. (Arte, v. 6). 
. Presidência da República. Casa Civil. Subchefia para Assuntos Jurídicos. Lei $\mathrm{n}^{0}$ 11.769, de 18 de agosto de 2008. Altera a Lei $\mathrm{n}^{\circ}$ 9.394, de 20 de dezembro de 1996, Lei de Diretrizes e Bases da Educação, para dispor sobre a obrigatoriedade do ensino da música na educação básica. Diário Oficial da União, Brasília, DF, 19 ago. 2008. Seção 1, p. 1.

Presidência da República. Casa Civil. Subchefia para Assuntos Jurídicos. Medida Provisória $\mathrm{n}^{\circ}$ 746, de 22 de setembro de 2016. Institui a Política de Fomento à Implementação de Escolas de Ensino Médio em Tempo Integral, altera a Lei $\mathrm{n}^{\circ}$ 9.394, de 20 de dezembro de 1996, que estabelece as diretrizes e bases da educação nacional, e a Lei n ${ }^{0} 11.494$ de 20 de junho 2007, que regulamenta o Fundo de Manutenção e Desenvolvimento da Educação Básica e de Valorização dos Profissionais da Educação, e dá outras providências. Diário Oficial da União, Brasília, DF, 23 set. 2016. Seção 1, p. 1.

CAPES. Banco de Teses e Dissertações. Disponível em: <http://bancodeteses.capes.gov.br/banco-teses/\#!/>. Acesso em: 10 out. 2016.

CORREA, Juliane Riboli. Construindo conhecimentos musicais e musicais-pedagógicos em grupo: experiências formativas na educação especial. 2013. 159 f. Dissertação (Mestrado em Educação) - Programa de Pós-Graduação em Educação, Universidade Federal de Santa Maria, Santa Maria, Rio Grande do Sul, 2013.

CUCCHI, Katia Daniela. Software musibraille: a interface entre educador leigo em musicografia braille e educando cego. 2013. 128 f. Dissertação (Mestrado em Educação Musical) - Programa de Pós-Graduação em Música, Universidade Federal da Bahia, Salvador, Bahia, 2013.

DROGOMIRECKI, Viviane Cristina. Educação Musical Inclusiva: Um estudo dos dados do projeto Arte Inclusão do Centro Profissional em Artes Basileu França (CEPABF). 2010. 82 f. Dissertação (Mestrado em Música) - Departamento de Linguística, Letras e Artes, Universidade Federal de Goiás, Goiânia, Góias, 2010.

FERREIRA, Nathalia Botura de Paula; DUARTE, Newton. As artes na educação integral: Uma apreciação histórico-crítica. Revista Ibero-americana de estudos em Educação, Araraquara, São Paulo, v. 6, n. 3, p. 115-126, 2011.

HAYASHI, Carlos Roberto Massao. Apontamentos sobre a coleta de dados em estudos bibliométricos e cientométricos. Filosofia e Educação (on-line), Campinas, São Paulo, v. 5, n. 2, p. 89102, out. 2013.

HAYASHI, Maria Cristina Piumbato Innocentini et al. Um estudo bibliométrico da produção científica sobre a educação jesuítica no Brasil colonial. Biblios, Lima, v. 8, p. 1-18, 2007.

IBICT. Biblioteca Digital Brasileira de Teses e Dissertações. Disponível em: < http://bdtd.ibict.br/ vufind/>. Acesso em: 10 out. 2016.

JOLY, Ilza Zenker Leme. Música e Educação especial: uma possibilidade concreta para promover o desenvolvimento de indivíduos. Educação (UFSM), Santa Maria, Rio Grande do Sul, v. 28, n. 2, p. 79-86, jul./ dez. 2003.

KEBACH, Patrícia; DUARTE, Rosângela. Educação Musical e Educação Especial: Processo de inclusão no sistema regular de ensino. Textos e Debates, Boa Vista, Roraima, n. 15, p. 98-111, 2012.

KUNTZE, Vivian Leichsenring. A relação do surdo com a música: representações sociais. 2014. 151 f. Dissertação (Mestrado em Música) - Programa de Pós-Graduação em Música do Centro de Artes, Universidade do Estado de Santa Catarina, Florianópolis, Santa Catarina, 2014. 
LOUREIRO, Cybelle Maria Veiga. Musicoterapia na educação musical especial de portadores de atraso do desenvolvimento leve e moderado na rede regular de ensino. 2006. $102 \mathrm{f}$. Dissertação (Mestrado em Música) - Escola de Música, Universidade Federal de Minas Gerais, Belo Horizonte, Minas Gerais, 2006.

LOURO, Viviane dos Santos; ALONSO, Luís Garcia; ANDRADE, Alex Ferreira de. Educação musical e deficiência: propostas pedagógicas. São José dos Campos, SP: Ed. Do Autor, 2006. 2012. 296p.

Fundamentos da aprendizagem musical da pessoa com deficiência. São Paulo: Ed. Som,

MACHADO, Pamela de Bortoli. A representação da inclusão social e digital por meio da música em documentários brasileiros. 2015. 159 f. Dissertação (Mestrado em Multimeios) - Instituto de Artes, Universidade Estadual de Campinas, Campinas, São Paulo, 2015.

MORALES, Daniela dos Santos. Música na docência de educadoras especiais: um estudo nas escolas de Santa Maria/RS. 2010. 89 f. Dissertação (Mestrado em Educação) - Programa de Pós-Graduação em Educação, Universidade Federal de Santa Maria, Santa Maria, Rio Grande do Sul, 2010.

PARANÁ (Estado). Secretaria de Estado da Educação. Diretrizes curriculares para a educação básica. Curitiba, 2008. Disponível em: <http://www.educadores.diaadia.pr.gov.br/arquivos/File/ diretrizes/dce_edf.pdf>. Acesso em: 13 out. 2016.

QUEIROZ, Luis Ricardo Silva. Música na escola: aspectos históricos da legislação nacional e perspectivas atuais a partir da Lei n. 11.769/2008. Revista da ABEM, Londrina, v. 20, n. 29, p. 23-38, jul./dez. 2012.

QUINTANILHA, José Carlos. Uma proposta de oficina de música para alunos com deficiência visual: construção de instrumentos musicais e performance. 2013. 148 f. Dissertação (Mestrado em Música) - Programa de Pós-Graduação em Música, Universidade Federal do Rio de Janeiro, Rio de Janeiro, 2013.

SANTOS, Claudia Eboli Corrêa dos. A educação musical especial: aspectos legais, históricos e metodológicos. 2008. 108 f. Dissertação (Mestrado em Música) - Pós-Graduação em Música do Centro de Letras e Artes, Universidade Federal do Estado do Rio de Janeiro, Rio de Janeiro, 2008.

SAVIANI, Dermeval. A educação musical no contexto da relação entre currículo e sociedade. In: Encontro Anual da Associação Brasileira de Educação Musical - ABEM, IX., 2000, Belém, PA. Anais... Belém, PA: ABEM, 2000. p. 33-42.

SILVA, Márcia Regina da; HAYASHI, Carlos Roberto Massao; HAYASHI, Maria Cristina Piumbato Innocentini. Análise bibliométrica e cientométrica: desafios para especialistas que atuam no campo. Revista de Ciência da Informação e Documentação, Ribeirão Preto, São Paulo, v. 2, n. 1, p. 110-129, 2011.

SOARES, Lisbeth. Formação e prática docente musical no processo de educação inclusiva de pessoas com necessidades especiais. 2006. 128 f. Dissertação (Mestrado em Ciências Humanas) - Pós-Graduação em Educação Especial, Universidade Federal de São Carlos, São Carlos, SP., 2006.

SOUZA, Catarina Shin Lima de. Música e inclusão: necessidades educacionais especiais ou necessidades profissionais especiais?. 2010. 157 f. Dissertação (Mestrado em Música) - Escola de Música, Universidade Federal da Bahia, Salvador, Bahia, 2010. 
TUDISSAKI, Shirlei Escobar. Ensino de música para pessoas com deficiência visual. 2014. 167 f. Dissertação (Mestrado em Música) - Instituto de Artes, Universidade Estadual Paulista, São Paulo, 2014.

VIANA, Ana Celia de Lima. Uma proposta de capacitação na área da educação musical especial. 2015. 125 f. Dissertação (Mestrado em Educação Especial) - Centro de Educação e Ciências Humanas, Universidade Federal de São Carlos, São Carlos, São Paulo, 2015.

Luciano Ribeiro Cil: Mestre em Metodologia para o Ensino de Linguagens e suas Tecnologias na Universidade Norte do Paraná - UNOPAR (2017); Graduado em Música pela Universidade Estadual de Londrina - UEL (2002). É servidor público da Secretaria do Estado da Educação do Paraná.

Taísa Grasiela Gomes Liduenha Gonçalves: Professora da Faculdade de Educação e do Programa de Pós-Graduação em Educação da Universidade Federal de Minas Gerais (UFMG). 